BMJ Open Sport \& Exercise Medicine

\title{
Exergaming can be an innovative way of enjoyable high-intensity interval training
}

\author{
Trine Moholdt, ${ }^{1}$ Stian Weie, ${ }^{2}$ Konstantinos Chorianopoulos, ${ }^{2}$ Alf Inge Wang, ${ }^{2}$ \\ Kristoffer Hagen ${ }^{2}$
}

To cite: Moholdt T, Weie S, Chorianopoulos K, et al. Exergaming can be an innovative way of enjoyable high-intensity interval training. BMJ Open Sport Exerc Med 2017;3: 0000258. doi:10.1136/bmjsem-2017000258

Accepted 20 June 2017

\section{CrossMark}

\section{${ }^{1}$ Department of Circulation and Medical Imaging, Faculty of Medicine, Norwegian University of Science and Technology, Trondheim, Norway \\ ${ }^{2}$ Department of Computer Science, Faculty of Information Technology and Electrical Engineering, Norwegian University of Science and Technology, Trondheim, Norway}

\section{Correspondence to} Dr Trine Moholdt, Department of Circulation and Medical Imaging, NTNU, Faculty of Medicine, Pbox 8905, 7491 Trondheim, Norway; trine.moholdt@ntnu. no

\section{ABSTRACT}

Objectives Exergames can replace sedentary time spent on computer gaming with physical activity. Previous research has found exergaming to elicit lightto-moderate exercise intensity. Our primary aim was to examine the exercise intensity of a newly developed biking exergame.

Methods Eight males (23.9 90.6 years) played the exergame (PLAY) and walked (WALK) on three separate occasions, with the condition counterbalanced and in random sequence within each day. They were asked to PLAY and WALK for a minimum of $15 \mathrm{~min}$ and then continue for as long as they wanted. We measured heart rate (HR), activity duration, caloric expenditure and subject-rated exertion and enjoyment (based on 0-10 Visual Analogue Scale, VAS). We used an average of each outcome variable across the 3 days in the analysis.

Results The average intensity during PLAY $(73 \% \pm$ $10 \%$ of $\mathrm{HR}_{\max }$ ) was significantly higher than that during WALK $\left(57 \% \pm 7 \%\right.$ of $\left.\mathrm{HR}_{\max }, \mathrm{p}=0.01\right)$. Participants spent $12.5 \pm 5.3 \mathrm{~min}$ at $80 \%-89 \%$ of $\mathrm{HR}_{\max }$ and $5.5 \pm 4.6$ min at $\geq 90 \%$ of $\mathrm{HR}_{\max }$ during PLAY, whereas intensity during WALK was $\leq 72 \%$ of $\mathrm{HR}_{\text {max }}$. The duration of PLAY was $44.3 \pm 0.7 \mathrm{~min}$ and of WALK $17.0 \pm 0.7 \mathrm{~min}(\mathrm{p}=0.01)$. The relative energy expenditure during PLAY was $7.6 \pm 0.7 \mathrm{kcal} / \mathrm{min}$ and during WALK $6.2 \pm 0.3 \mathrm{kcal} / \mathrm{min}(\mathrm{p}<0.01)$. The enjoyment of PLAY (VAS 8.7 \pm 0.1 ) was higher than that of WALK (VAS $3.9 \pm 1.8, p=0.01$ ).

Conclusions Exergaming can be an innovative way of enjoyable high-intensity training.

\section{INTRODUCTION}

Physical inactivity is now the fourth leading cause of death in the world, responsible for $9 \%$ of premature mortality, ${ }^{1}$ and sedentary time is independently associated with increased risk for all-cause mortality, cardiovascular disease incidence and mortality, and type 2 diabetes. ${ }^{2}$ Screen-based entertainment (television, computer and other gaming devices) is an important indicator of non-occupational sedentary behaviour, ${ }^{3}$ and according to reports on temporal trends in screen-time use, this behaviour is

\section{What are the new findings}

Playing of an active video game (exergame) in young men elicited high exercise intensity.

- The heart rate response to this biking exergame was similar to traditional high-intensity interval training.

- The men found the game play to be highly enjoyable.

- This form of training could be a viable option to increase physical activity in individuals who are not motivated by exercise per se.

increasing in both adolescents and adults. ${ }^{4}$ Furthermore, it was estimated that by replacing $30 \mathrm{~min}$ of sedentary time per day with an equal amount of light activity, the risk of mortality could be reduced by $14 \%$, whereas replacing sedentary time with moderate-to-vigorous activity gave a $50 \%$ risk reduction. ${ }^{6}$ Owing to the inverse doseresponse relationship between exercise intensity and mortality, a lower dose of vigorous aerobic activity (ie, $\geq 60$ weekly minutes) compared with moderate intensity (ie, $\geq 150$ weekly minutes) is recommended to improve health in adults. ${ }^{7}$ High-intensity interval training is suggested to have a role in the prevention of cardiometabolic diseases, ${ }^{8}$ as this form of training is superior to moderate-intensity training on several important prognostic factors (peak oxygen uptake, glycaemic control, endothelial function and quality of life). However, for any exercise programme to be effective, motivation to start and to continue adhering to the activity is of key importance.

Exergaming is the use of video games in an exercise activity and can be a means to produce increased physical activity. ${ }^{9}{ }^{10}$ It has been shown to be an enjoyable activity for adolescents, young adults and older adults, thereby having a potential for 
sustained activity participation. ${ }^{11}{ }^{12}$ However, previous studies on the physiological responses to exergaming have found that such gaming elicited light-to-moderate exercise intensity. ${ }^{12-14}$

The primary aim of our study was to assess the exercise intensity reached during playing of a newly developed biking exergame called 'Pedal Tanks'. The participants were asked to play the exergame and to walk briskly in a randomised and counterbalanced sequence. Our hypothesis was that exercise intensity would be high ( $>85 \%$ of heart rate maximum, $\mathrm{HR}_{\max }$ ) in periods during the exergaming. Our secondary aims were to determine the energy expenditure, enjoyment, perceived exertion and self-selected duration of exergaming compared with walking.

\section{METHODS}

\section{Participants and design}

Eight male university students visited our laboratory on four separate days to complete one familiarisation session and three experimental sessions. Table 1 outlines the participants' characteristics. The subjects were recruited via word of mouth and had basic familiarity of computer games (all reported to play computer games for more than 5 hours/week) but not with cycle-based gaming. All participants signed a written informed consent before participation. We submitted the study protocol to the Regional Committee for Medical and Health Research Ethics (REK-midt 2015/2262) and to the Norwegian Centre for Research Data. Both bodies evaluated the study as not subject to notification.

\section{Pedal Tanks exergame}

Pedal Tanks is a newly created multiplayer online game, where the players control a tank by using the pedals of the bike and six buttons on the handlebars of a regular stationary bike. ${ }^{15}$ The game was designed by some of the authors (KH, SW, KC and AIW) and is not yet commercially available. Four individuals play together, in teams of two, competing to outmanoeuvre the opposing team. The goal of the game is to capture the opponents' flag. Movement in the game is encouraged through the goal; guarding your own flag from

\begin{tabular}{lc}
\hline \multicolumn{2}{l}{ Table $1 \quad$ Participants' characteristics } \\
\hline Characteristics & $\mathbf{n = 8}$ \\
\hline Age (years) & $23.9 \pm 0.6$ \\
\hline Weight $(\mathrm{kg})$ & $85.1 \pm 9.0$ \\
\hline Height $(\mathrm{m})$ & $1.83 \pm 0.5$ \\
\hline Body mass index $\left(\mathrm{kg} / \mathrm{m}^{2}\right)$ & $25.4 \pm 3.8$ \\
\hline Exercise (hours/week) & $1.9 \pm 1.9$ \\
\hline Gaming (hours/week) & $18.4 \pm 10.5$ \\
\hline
\end{tabular}

opponents and getting their flag back to your base. In order to further motivate movement, the players also regenerate ammunition that can be used to shoot an opponent based on the distance moved within the game, generated by cycling (figure 1). Each game consists of a preselected number of rounds that end once one team manages to capture the flag or when a 2 min timer runs out. The Pedal Tanks exergame was designed as a co-located multiplayer game, as the social context has proven to improve the player enjoyment and performance. ${ }^{16}$

\section{Experimental trial}

This was a within-subject study where the participants played Pedal Tanks (PLAY) and walked outside (WALK) on three separate days, with the condition counterbalanced and in random sequence within each day. The order of conditions was randomised for the first group of four subjects using a random number generator. The second group was given the opposite order as the first group. The participants rested in the laboratory for $15 \mathrm{~min}$ between the two conditions. Before the experiment started, the participants practised the Pedal Tanks game for $15 \mathrm{~min}$ to familiarise with the exergame. We asked the participants to do both activities for a minimum of $15 \mathrm{~min}$ and to continue for as long as they wanted up to $60 \mathrm{~min}$.

The PLAY condition comprised participants playing the Pedal Tanks at self-selected exercise intensity. The participants played in 'best-of-5-rounds', meaning that they played until one team won for the third time. Each of these rounds has a maximum of $2 \mathrm{~min}$. Inbetween each game, they had a short break $(15 \mathrm{~s})$, and between each 'best-of-5-round' they had a 3 min break.

In the WALK condition, the participants walked outdoors at a self-selected moderately paced speed, with no supervision from the researchers. They walked in groups of four in order to mimic the social interaction in PLAY. The weather was $14^{\circ} \mathrm{C}-18^{\circ} \mathrm{C}$, cloudy but not raining. The reason for choosing moderate-intensity walking as a control condition was that such brisk walking performed in bouts of at least $10 \mathrm{~min}$ is recommended in the guidelines for physical activity to promote health in adults.

\section{Measurements}

The participants filled out a questionnaire on hours per week of exercise training and gaming. The participants wore HR monitors (Polar A300) and physical activity monitors (SenseWear Armband, Body Media) during the activities. We averaged HR over the three sessions of each condition and reported intensities as percentage of estimated $\mathrm{HR}_{\max }$ using the formula 211-0.64 ×age. ${ }^{17}$ Exercise intensity was also categorised into HR zones, using the Polar Flow training analysis tool. From the activity monitors, we registered the estimated absolute and relative energy expenditure (in total kilocalorie and kilocalorie per minute, 


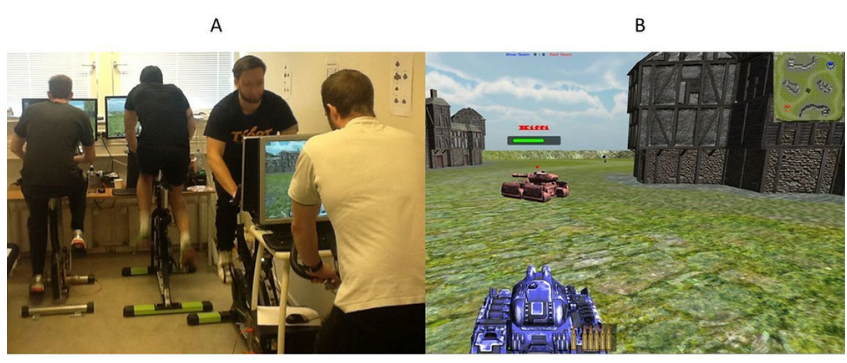

Figure 1 (A) Experimental set-up of PLAY. (B) The Pedal Tanks exergame.

respectively). Immediately after each session, the participants rated their perceived exertion and enjoyment of the activity on $10 \mathrm{~cm} 0-10$ Visual Analogue Scales (VAS).

\section{Statistical analysis}

Statistical analysis was performed using Stata version 13.1. We did not perform a sample size calculation prior to the data collection. The reason for this was that this trial was considered a pilot study. We used the Shapiro-Wilk test to check for normality of data. The duration of both activities, perceived exertion of PLAY, average HR during play and time spent in different intensity zones were not normally distributed. We therefore used Wilcoxon signed rank tests to assess differences between these outcome variables of the two activities (WALK and PLAY). We used paired-samples t-test to assess differences between the remaining outcome measures of the two activities. Data are presented as mean $\pm \mathrm{SD}$ unless otherwise stated. The significance level was set at $\mathrm{p}<0.05$.

\section{RESULTS}

The participants ranked the rate of perceived exertion of PLAY to $8.4 \pm 1.1$ and WALK to $1.7 \pm 0.9$ on VAS $(\mathrm{p}=0.01)$. The average HR during PLAY was $73 \% \pm 10 \%$ of $\mathrm{HR}_{\max }$, whereas it was $57 \% \pm 7 \%$ of $\mathrm{HR}_{\max }$ during WALK $(p=0.01)$. The maximum HR reached was $91 \% \pm 9 \%$ during PLAY and $66 \% \pm 5 \%$ of $\mathrm{HR}_{\max }$ during WALK ( $p<0.01$, figure 2$)$. We observed no tendency of a practice effect in average HR or maximum HR reach during the three trials. Participants spent $12.5 \pm 5.3 \mathrm{~min}$ at $80 \%-89 \%$ of $\mathrm{HR}_{\max }$ and $5.5 \pm 4.6 \mathrm{~min}$ at $\geq 90 \%$ of $\mathrm{HR}_{\text {max }}$ during PLAY. The intensity during WALK was mainly $<70 \%$ of $\mathrm{HR}_{\max }$, with $0.7 \pm 0.9 \mathrm{~min}$ at $70 \%-79 \%$ of $\mathrm{HR}_{\max }$ (table 2). Figure 3 shows a typical HR curve for one of the participants during PLAY. The duration of PLAY was $44.3 \pm 0.7 \mathrm{~min}$ and of WALK $17.0 \pm 0.7 \mathrm{~min}$ $(p=0.01)$. The enjoyment of PLAY (VAS $8.7 \pm 0.1)$ was higher than that of WALK (VAS $3.9 \pm 1.8, \mathrm{p}=0.01$ ) (figure 4).

The estimated absolute energy expenditure during PLAY $(334.6 \pm 31.4 \mathrm{kcal})$ was significantly higher than that during WALK $(105.1 \pm 5.8 \mathrm{kcal}, \mathrm{p}<0.01)$. The relative energy expenditure during PLAY $(7.6 \pm 0.7 \mathrm{kcal} /$ min) was also significantly higher than that during WALK $(6.2 \pm 0.3 \mathrm{kcal} / \mathrm{min}, \mathrm{p}<0.01)$.

\section{DISCUSSION}

\section{Main findings}

We investigated the physiological cost and enjoyment of a newly developed multiplayer biking exergame. The exercise intensity during exergaming was moderate to high, with intervals reaching $~ 90 \%$ of $\mathrm{HR}_{\max }$ and with more than one-third of the total activity time spent above $80 \%$ of $\mathrm{HR}_{\max }$. The participants rated the enjoyment of exergaming high, and they voluntarily continued to play approximately 30 min longer than they were asked. The exercise intensity, as measured HR and subjective rating of perceived exertion, and enjoyment of exergaming were significantly higher than of walking.

\section{Exercise intensity}

In contrast to our findings, previous studies on the physiological responses to exergaming have found that such game play elicited light-to-moderate intensity

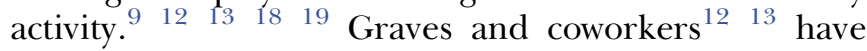
measured the energy expenditure of adolescents, young adults and older adults while playing traditional (inactive) computer games, Nintendo Wii (exergames), as well as in various sports and activities. They found the exercise intensity during exergaming to be significantly higher than during sedentary computer games; however, the intensity of the exergames was comparable with bowling ${ }^{13}$ and significantly lower than of treadmill walking or jogging. ${ }^{12}$ Even if low-intensity activities might attenuate the detrimental effects of prolonged sitting, ${ }^{20}$ we argue that activities of moderate and high intensities should be advocated to achieve superior health benefits. Maintaining a good cardiorespiratory fitness over years is strongly and independently associated with improved health outcomes and survival. ${ }^{21} 22$ According to recent systematic reviews, ${ }^{23-25}$ high-intensity interval training is more effective on improving cardiometabolic risk and aerobic capacity than other forms of exercise in various populations. In the present study, the exercise intensity

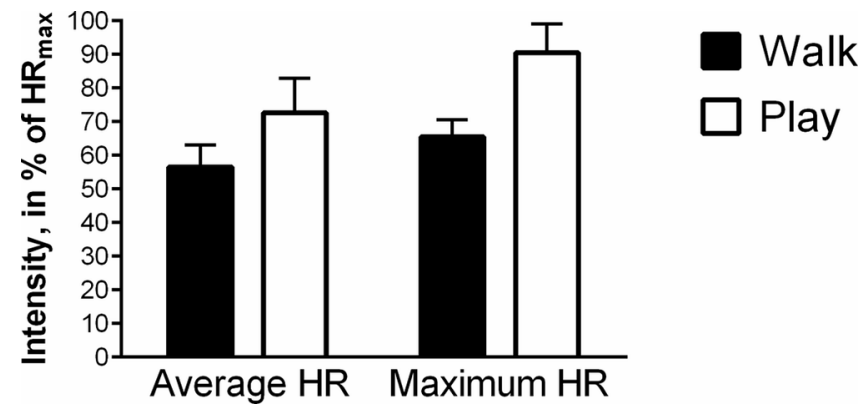

Figure 2 Exercise intensity during WALK (black bars) and PLAY (white bars). Error bars represent SD. HR, heart rate. 


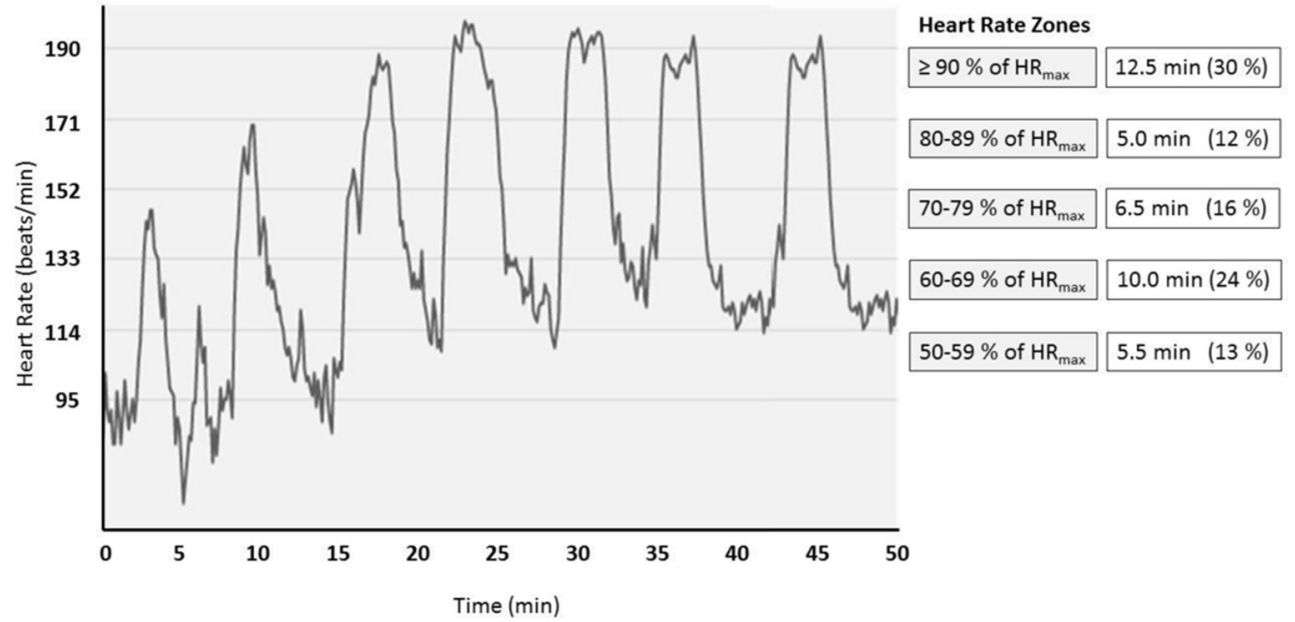

Figure 3 Heart rate (HR) curve of one participant during PLAY.

during exergaming was similar to conventional highintensity interval training, indicating that such game play would significantly improve the participants' cardiorespiratory fitness if undertaken over time. There is still limited evidence available to conclude on the long-term efficacy of exergaming for improvement in cardiorespiratory fitness, and further studies should examine the chronic adaptations after exergaming. However, Warburton and coworkers ${ }^{26}$ showed an $11 \%$ increase in maximal oxygen uptake after 6 weeks of exergaming on a stationary bike for $30 \mathrm{~min}$ on 3 days/ week.

It is hard to overestimate the health benefits of regular exercise training, as physical activity is associated with reduced chances of acquiring more than 25 chronic diseases, such as cardiovascular disease, type 2 diabetes, several cancer forms and psychological disorders. ${ }^{27}$ Nevertheless, many adults fail to meet the recommended level of $150 \mathrm{~min}$ of moderate-intensity physical activity or $75 \mathrm{~min}$ of vigorous intensity physical activity per week.

\section{Enjoyment}

Perceived enjoyment of an activity is an important determinant for the time allocated to an activity. In general, people are inclined to undertake activities that make them feel good and to avoid activities that do

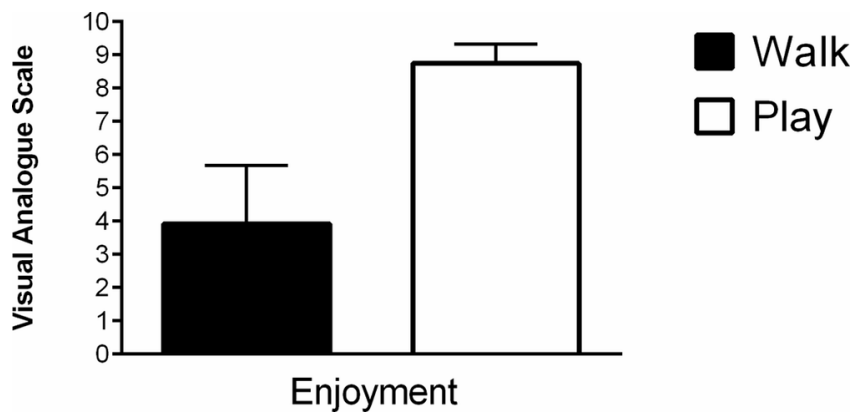

Figure 4 Self-rated level of enjoyment during WALK (black bar) and PLAY (white bar). Error bars represent SD. not. ${ }^{28}$ The tendency of humans to maximise pleasure and minimise displeasure can also be proposed as a mechanism for exercise adherence, ${ }^{29}$ and affective responses during exercise have been shown to predict future physical activity. ${ }^{30}$ The use of enjoyable exergames can therefore be a fruitful strategy for promoting physical activity, in particular for those less motivated by more traditional exercise.

In our study, the participants rated the enjoyment of exergaming as high even though the intensity was vigorous. Some previous studies have shown that the affective responses to high-intensity training are worse than those associated with moderate-intensity exercise $^{31} 32$ and, therefore, recommend moderate intensity to increase future adherence to exercise. We do, however, argue that our results indicate that exergaming can be a fun and acceptable high-intensity training intervention. The specific exergame played in our study (Pedal Tanks) included gameplay features from popular ordinary (non-exergame) games, such as player progression and team-based multiplayer design. Such game qualities are associated with player enjoyment and can potentially increase the adherence to the exergame over a longer period. Exercise persistence during exergaming can increase if you are playing with a partner who shows signs of fatigue over time. ${ }^{33}$ In our study, the participants changed teams and position between each test day in order to minimise the influence of different social and environmental contexts on exercise intensity and enjoyment.

\section{Limitations}

Limitations of the present study include a small sample. Further, participation in the study was voluntary and therefore the rating of enjoyment of exergaming may be higher than for those who did not want to participate. Hence, we do not know if our results can be generalised beyond our sample. Energy expenditure was not directly measured but estimated using an activity monitor. The SenseWear armband 
Table 2 Time spent in different heart rate (HR) zones during WALK and PLAY

\begin{tabular}{|c|c|c|c|c|c|c|}
\hline \multirow[b]{2}{*}{ HR zone } & \multicolumn{2}{|c|}{ Absolute time (min) } & \multirow[b]{2}{*}{$\mathbf{p}$} & \multicolumn{2}{|c|}{ Relative time in $\%$ of whole activity time } & \multirow[b]{2}{*}{$\mathbf{p}$} \\
\hline & Walk & Play & & Walk & Play & \\
\hline $50 \%-59 \%$ of $\mathrm{HR}_{\max }$ & $8.7 \pm 4.9$ & $4.4 \pm 3.9$ & 0.02 & $55.4 \pm 29.6$ & $9.8 \pm 8.1$ & 0.02 \\
\hline $60 \%-69 \%$ of $\mathrm{HR}_{\max }$ & $4.8 \pm 4.7$ & $9.4 \pm 2.1$ & 0.04 & $26.9 \pm 25.1$ & $20.3 \pm 5.2$ & 0.67 \\
\hline $70 \%-79 \%$ of $\mathrm{HR}_{\max }$ & $0.7 \pm 0.9$ & $9.3 \pm 3.0$ & 0.01 & $4.6 \pm 7.0$ & $20.2 \pm 5.8$ & 0.01 \\
\hline $80 \%-89 \%$ of $\mathrm{HR}_{\max }$ & - & $12.5 \pm 5.3$ & 0.01 & - & $26.7 \pm 11.3$ & 0.01 \\
\hline$\geq 90 \%$ of $\mathrm{HR}_{\max }$ & - & $5.5 \pm 4.6$ & 0.01 & - & $11.8 \pm 9.6$ & 0.01 \\
\hline
\end{tabular}

Not reported when $\mathrm{HR} \leq 49 \%$ of $\mathrm{HR}_{\max }$ during activites (11.2\% in PLAY and $12.7 \%$ in WALK).

has, however, been found to have a very good linear correlation with indirect calorimetry, although with a slight underestimation of energy expenditure during cycling. ${ }^{34}$ We chose not to use indirect calorimetry measurements in the present study as we think that wearing a mask or mouthpiece would have affected the rating of enjoyment and the chosen duration time of the activities. Another limitation to the validity of our measurements is the estimated $\mathrm{HR}_{\max }$ used in calculating the relative intensity. However, this does not limit the value of the comparison between the two activities (walking vs exergaming). In our study, the time frame of assessments was short, and we investigated only acute physiological and enjoyment responses. We need longitudinal studies to determine if these responses will sustain and to assess if exergaming can continue to be an enjoyable way of doing high-intensity training in the long run. One possible explanation for why the participants chose to spend more time playing than walking might have been the novelty of the PLAY task. Users of a new exergame might want to spend more time with the game in order to explore and understand it. Outside walking was chosen as the control condition. We realise that a high intensity would not be reached during brisk walking in our participants. The reason for choosing walking as a comparison was mainly that we wanted to investigate the enjoyment and self-selected duration of this activity compared with exergaming and not as much the intensity reached during the two activities. Given the novelty of the exergame, the focus was on whether high-intensity interval training could be possible and not comparison with other types of interval training. Further work should also consider the comparison of intensity, enjoyment and duration of exergaming versus other types of physical activity and exercise, in particular comparing exergaming with traditional high-intensity interval training.

\section{CONCLUSION}

Playing a biking exergame elicited high exercise intensity and was perceived as enjoyable. This form of training could be a viable option to increase physical activity in individuals who are not motivated by exercise per se.

Contributors SW, KC, AIW, KH and TM designed the study. SW and KH collected the data. $\mathrm{KH}$ and TM analysed the data. TM wrote the manuscript draft. SW, KC, AIW and KH revised the manuscript. All authors approved the final manuscript.

Competing interests None declared.

Patient consent Obtained.

Ethics approval We submitted the study protocol to the Regional Committee for Medical and Health Research Ethics (REK5midt 2015/2262) and to the Norwegian Centre for Research Data. Both bodies evaluated the study as not subject to notification.

Provenance and peer review Not commissioned; externally peer reviewed. Data sharing statement All data from the study is available on request.

Open Access This is an Open Access article distributed in accordance with the Creative Commons Attribution Non Commercial (CC BY-NC 4.0) license, which permits others to distribute, remix, adapt, build upon this work noncommercially, and license their derivative works on different terms, provided the original work is properly cited and the use is non-commercial. See: http:// creativecommons.org/licenses/by-nc/4.0/

(c) Article author(s) (or their employer(s) unless otherwise stated in the text of the article) 2017. All rights reserved. No commercial use is permitted unless otherwise expressly granted.

\section{REFERENCES}

1. Lee IM, Shiroma EJ, Lobelo F, et al. Effect of physical inactivity on major non-communicable diseases worldwide: an analysis of burden of disease and life expectancy. Lancet 2012;380:219-29.

2. Biswas A, Oh PI, Faulkner GE, et al. Sedentary time and its association with risk for disease incidence, mortality, and hospitalization in adults: a systematic review and meta-analysis. Ann Intern Med 2015;162:123-32.

3. Clark BK, Sugiyama T, Healy GN, et al. Validity and reliability of measures of television viewing time and other non-occupational sedentary behaviour of adults: a review. Obes Rev 2009;10:7-16.

4. Duncan MJ, Vandelanotte C, Caperchione C, et al. Temporal trends in and relationships between screen time, physical activity, overweight and obesity. BMC Public Health 2012;12:1060.

5. Bucksch J, Sigmundova D, Hamrik Z, et al. International trends in adolescent screen-time behaviors from 2002 to 2010. The Journal of adolescent health: official publication of the Society for Adolescent Medicine, 2016.

6. Schmid D, Ricci C, Baumeister SE, et al. Replacing sedentary time with physical activity in relation to mortality. Med Sci Sports Exerc 2016;48:1312-9.

7. Haskell WL, Lee IM, Pate RR, et al. Physical activity and public health: updated recommendation for adults from the American College of Sports Medicine and the American Heart Association. Circulation 2007;116:1081-93. 
8. Wisløff U, Coombes JS, Rognmo $\varnothing$. CrossTalk proposal: high intensity interval training does have a role in risk reduction or treatment of disease. J Physiol 2015;593:5215-7.

9. Höchsmann C, Schüpbach M, Schmidt-Trucksäss A. Effects of exergaming on physical activity in overweight individuals. Sports Med 2016;46:845-60.

10. Sween J, Wallington SF, Sheppard V, et al. The role of exergaming in improving physical activity: a review. J Phys Act Health 2014;11:864-70.

11. Monedero J, Lyons EJ, O'Gorman DJ. Interactive video game cycling leads to higher energy expenditure and is more enjoyable than conventional exercise in adults. PLoS One 2015;10:e0118470.

12. Graves LE, Ridgers ND, Williams K, et al. The physiological cost and enjoyment of Wii Fit in adolescents, young adults, and older adults. $J$ Phys Act Health 2010;7:393-401.

13. Graves L, Stratton G, Ridgers ND, et al. Energy expenditure in adolescents playing new generation computer games. $\mathrm{Br} J$ Sports Med 2008;42:592-4.

14. LeBlanc AG, Chaput JP, McFarlane A, et al. Active video games and health indicators in children and youth: a systematic review. PLoS One 2013;8:e65351.

15. Hagen K, Weie S, Chorianopoulos K, et al; Pedal Tanks. In: Chorianopoulos K, Divitini M, Baalsrud Hauge J, eds. Entertainment Computing - ICEC 2015: 14th international conference, ICEC 2015, Trondheim, Norway. Cham: Springer International Publishing 2015:539-44.

16. Gajadhar BJ, de Kort YAW, IJsselsteijn WA, et al. Shared Fun Is Doubled Fun: Player Enjoyment as a Function of Social Setting. In: Markopoulos P, de Ruyter B, ljsselsteijn W, Fun and Games: second International Conference, Eindhoven, The Netherlands. Berlin, Heidelberg: Springer Berlin Heidelberg, 2008:106-17.

17. Nes BM, Janszky I, Wisløff U, et al. Age-predicted maximal heart rate in healthy subjects: the HUNT fitness study. Scand J Med Sci Sports 2013;23:697-704.

18. Kraft JA, Russell WD, Bowman TA, et al. Heart rate and perceived exertion during self-selected intensities for exergaming compared to traditional exercise in college-age participants. J Strength Cond Res 2011;25:1736-42.

19. Siegel SR, L Haddock B, Dubois AM, et al. Active video/arcade games (exergaming) and energy expenditure in college students. Int J Exerc Sci 2009;2:165-74.

20. Crespo NC, Mullane SL, Zeigler ZS, et al. Effects of standing and light-intensity walking and cycling on 24-h glucose. Med Sci Sports Exerc 2016;48:2503-11.

21. Laukkanen JA, Zaccardi $\mathrm{F}$, Khan $\mathrm{H}$, et al. Long-term change in cardiorespiratory fitness and all-cause mortality: a population-based follow-up study. Mayo Clin Proc 2016;91:1183-8.
22. Chow LS, Odegaard AO, Bosch TA, et al. Twenty year fitness trends in young adults and incidence of prediabetes and diabetes: the CARDIA study. Diabetologia 2016;59:1659-65.

23. García-Hermoso A, Cerrillo-Urbina AJ, Herrera-Valenzuela T, et al. Is high-intensity interval training more effective on improving cardiometabolic risk and aerobic capacity than other forms of exercise in overweight and obese youth? A meta-analysis. Obes Rev 2016;17:531-40.

24. Costigan SA, Eather N, Plotnikoff RC, et al. High-intensity interval training for improving health-related fitness in adolescents: a systematic review and meta-analysis. Br J Sports Med 2015;49:1253-61.

25. Weston KS, Wisløff U, Coombes JS. High-intensity interval training in patients with lifestyle-induced cardiometabolic disease: a systematic review and meta-analysis. Br J Sports Med 2014; 48:1227-34.

26. Warburton DE, Bredin SS, Horita LT, et al. The health benefits of interactive video game exercise. Applied physiology, nutrition, and metabolism = physiologie appliquee. Nutrition 2007; 32:655-63.

27. Warburton DE, Nicol CW, Bredin SS. Health benefits of physical activity: the evidence. CMAJ 2006;174:801-9.

28. Bechara A, Damasio $H$, Damasio AR. Emotion, decision making and the orbitofrontal cortex. Cereb Cortex 2000;10:295-307.

29. Ekkekakis P, Hall EE, Petruzzello SJ. Variation and homogeneity in affective responses to physical activity of varying intensities: an alternative perspective on dose-response based on evolutionary considerations. J Sports Sci 2005;23:477-500.

30. Rhodes RE, Kates $A$. Can the affective response to exercise predict future motives and physical activity behavior? A systematic review of published evidence. Ann Behav Med 2015;49:715-31.

31. Saanijoki T, Nummenmaa L, Eskelinen JJ, et al. Affective responses to repeated sessions of high-intensity interval training. Med Sci Sports Exerc 2015;47:2604-11.

32. Ekkekakis $P$, Hall EE, Petruzzello SJ. The relationship between exercise intensity and affective responses demystified: to crack the 40-year-old nut, replace the 40-year-old nutcracker!. Ann Behav Med 2008;35:136-49.

33. Max EJ, Samendinger S, Winn B, et al. Enhancing aerobic exercise with a novel virtual exercise buddy based on the Köhler effect. Games Health J 2016;5:252-7.

34. Casiraghi F, Lertwattanarak R, Luzi L, et al. Energy expenditure evaluation in humans and non-human primates by SenseWear Armband. Validation of energy expenditure evaluation by SenseWear Armband by direct comparison with indirect calorimetry. PLoS One 2013;8:e73651. 